\title{
Automatización De Una Sala De Ordeño Para El Control De Compuertas, Dosificación De Alimento Y Medición De Leche, Caso De Estudio: Espoch-Ecuador
}

\author{
Freddy Patricio Ajila Zaquinaula (Ing. Info.Msc.) \\ Christian Sánchez-Acosta (Ing. Electrónica, Control y Redes \\ Industriales) \\ Juan Carlos Pacheco-Reinoso (Ing. Electrónica, Control y \\ Redes Industriales) \\ Arisdorgan Diéguez Almaguer (Lic. en Educación. MSc.)
}

Universidad/ Escuela Superior Politécnica de Chimborazo de la República

del Ecuador

Doi: 10.19044/esj.2018.v14n30p419 URL:http://dx.doi.org/10.19044/esj.2018.v14n30p419

\begin{abstract}
This paper focuses on the development of an automatic system for a milking room in the Tunshi Experimental Center of the Polytechnic Superior School of Chimborazo, Ecuador. This research uses a theoretical, empirical and statistical methods, and it was carried out using the SCADA system. The proposal was integrated by three subsystems that fulfill specific functions. These functions are: gate control system, feed dosage control system, and milk measurement system. These subsystems use a Programmable Logic Controller (PLC) that is responsible for communicating with devices such as sensors, electrovalves, and pneumatic actuators. The PLC communicates through a process control server (PCS) using a Control Software developed in LabVIEW, which is responsible for the monitoring and controlling the SCADA System. This is done in order to propose a viable option in a bid to increase the competitiveness of the livestock sector.
\end{abstract}

Keywords: Food dosing system, programmable logic controller, automatic milking control system, automatic gate control system, automatic milk measuring system

\section{Resumen}

El presente artículo tiene como objetivo el desarrollo de un sistema automatizado para una sala de ordeño en el Centro Experimental Tunshi de la Escuela Superior Politécnica de Chimborazo-Ecuador. Para ello, se utilizan 
los métodos teóricos, empíricos y estadísticos acordes a la investigación y se realiza la misma en base al sistema SCADA. La propuesta está integrada por tres subsistemas que cumplen funciones específicas; estos son: sistema de control de compuertas, sistema de dosificación de alimento y sistema de medición de leche; subsistemas que utilizan un Controlador Lógico Programable (CLP) que se encarga de la comunicación con los dispositivos como sensores, electroválvulas y actuadores neumáticos. El PLC se comunica mediante un servidor de control de procesos (OPC) a un Software de Control desarrollado en LabVIEW que se encarga del monitoreo y control del Sistema SCADA, para proponer así una opción viable al esfuerzo de aumentar la competitividad del sector ganadero.

Palabras claves: Sistema de dosificación de alimentos, controlador lógico programable, sistema automático de control de ordeño, sistema automático de control de compuertas, sistema automático de medición de leche

\section{Introduction}

A medida que el hombre alcanza niveles de desarrollo científico técnicos cada vez mayores, se incrementan sus esfuerzos para automatizar las diferentes operaciones que realiza cotidianamante, y el proceso de ordeño del ganado vacuno no es ajeno a esta tendencia. Las primeras ideas para automatizarlo totalmente se generan a mediados de los años setenta, motivadas fundamentalmente por el incremento de los costos por mano de obra en varios países.

Un paso importante en la automatización del ordeño lo constituye la aparición de sistemas confiables para la identificación de las vacas, así como el desarrollo de retiradores autómaticos para las salas de ordeño. A principios de los años ochenta, esta automatización se incrementa por la aparición de equipos para registrar la producción de leche y detectar los problemas de salud de las vacas.

La aplicación de las nuevas tecnologías trae consigo la redución considerable de la mano de obra necesaria para la actividad, esto favorece la mejora del indicador de la productividad del trabajoy la labor de los operarios se reduce. El paso final en la automatización del ordeño parece ser entonces el desarrollo de sistemas de colocación automatizada de los casquillos.

Al final de los años ochenta y a principios de los años noventa, una serie de principios de colocación de unidades de ordeño fueron estudiados en varios institutos de investigaciones en toda Europa. Sin embargo, tomó casi una década convertir la técnica de ubicar pezones y colocar casquillos en sistemas de ordeños automatizados, íntegros y confiables, instalándose los primeros robots de ordeño en 1992. 
Actualmente la ganadería lechera atraviesa cambios masivos debido a varias razones: el aumento del tamaño de los fincas lecheras, el interés por aumentar la calidad de la leche, aumentar el rendimiento productivo por cada vaca, así como reducir la cantidad de trabajo que realiza cada operador.

Por ello, este artículo se centra en desarrollo del Sistema automatizado (SCADA), el cuales la primera parte de la solución integral del proyecto de investigación denominado "Automatización de los procesos del Centro Experimental Tunshi",', perteneciente a la Escuela Superior Politécnica de Chimborazo del Ecuador, donde se automatizará el control de compuertas, la dosificación de alimentos y la medición de leche.

\section{Desarrollo}

El avance en los sistemas ganaderos se asocia a la implementación de tecnologías en la producción y a la mejora de sus ingresos. Ejemplos de dicha implementación podrían ser (Torres et al., 2014); para la automatización de compuertas se puede usar un sistema electro-neumático que por medio de electroválvulas permita la apertura y cierre de compuertas (Boyer \& Stuart, 2009); un comedero automatizado pretende mejorar el proceso de alimentación del ganado bovino, mejorar la productividad de las granjas, dosificar de forma precisa el alimento para cada animal e identificar el animal de forma única y automatizada (Duque et al., 2015); el proceso de ordeño puede ser tradicional o se pueden emplear otros métodos como una ordeñadora móvil (Filgueira \& Raimúndez, 2012).

En nuestro entorno regional y nacional los sistemas automáticos para el control de compuertas, alimentación y ordeño funcionan por separado, por lo tanto, se propone el diseño e implementación de un sistema automatizado SCADA (Supervisory Control and Data Acquisition) (MONOGRAFICO) que permite integrar la apertura y cierre de compuertas, la dosificación exacta del alimento y la medición de la leche producida por cada animal, esto con el fin de reducir los costes de producción y aumentar la competitividad, y considerando que una de las vías consiste en incrementar el nivel tecnológico de las explotaciones ganaderas para conseguir ser más eficientes (Cobo Ruiz, 2015). El sistema SCADA propuesto est'́q integrado por tres subsistemas que cumplen las siguientes funciones específicas:

\section{A. Sistema de control de compuertas}

Este subsistema se encarga de abrir y cerrar la compuerta de entrada a la sala de ordeño y las compuertas de cada cubículo a partir de la identificación del animal; para ello utiliza un sistema de accionamiento neumático. 


\section{B. Sistema de dosificación de alimento}

Identificado el animal dentro del cubículo, este subsistema se encarga de consultar en la base de datos informática para así dosificar la cantidad exacta de alimento que debe consumir.

\section{Sistema de medición de leche}

Usa los datos de la pantalla electrónica del sistema de ordeño semiautomático que actualmente existe, ya que no es posible acceder a la base de datos de este sistema porque es software propietario. Este subsistema identifica, por medio de un sensor, el momento cuando se sueltan las pezoneras de la vaca y toma una foto a la pantalla; esta imagen es convertida por medio de la técnica de visión artificial a formato decimal y almacenada en la base de datos.su desarrollo.

\section{Metodología}

Para definir los requerimientos del sistema automático se utilizó la técnica de observación directa de procesos, la misma que permitió diseñar el sistema automático de procesos para la sala de ordeño del Centro Experimental Tunshi de la Escuela Superior de Chimborazo. La sala de ordeño contaba con: una puerta de acceso principal, cuatro cubículos de 1,5 x 3 metros de longitud con compuertas de entrada y salida de 0,8 x 0,8 metros y un peso aproximado de 10 Kilogramos para cada compuerta. El sistema automatizado SCADA desarrollado en LABVIEW utiliza un Controlador Lógico Programable (PLC) que permite al sistema controlar y monitorear los tres subsistemas antes mencionados. Al PLC se conectan todos los sensores y actuadores de tal manera que pueda recibir datos del software LABVIEW y de los sensores, para así interpretarlos y enviar señales que activen los actuadores encargados de abrir-cerrar compuertas, dosificar la cantidad de alimento exacto y medir la cantidad de leche producida por cada animal.

Con MySQL se creó la base de datos para guardar información del sistema de medición de leche, y para quetambién permita consultas al Sistema de dosificación de alimento. El Sistema SCADA se implementó con los siguientes materiales:

\section{Controlador Lógico Programable SIMATIC S7-1200 CPU 1214C}

El PLC SIMATIC S7-1200 representa la solución más versátil, segura e idónea para el control y automatización de procesos, gracias a que posee una gama completa de elementos de control y visualización que garantizan la funcionalidad eficiente en cualquier campo. Un PLC es un equipo electrónico programable por el usuario capaz de procesar de señales binarias y mantener el control en un entorno industrial de máquinas o procesos lógicos que pueden ser o no secuenciales. Además de poder ser programados, son automáticos; es 
decir, son aparatos que comparan las señales emitidas por la máquina controlada y toman decisiones en base a las instrucciones programadas para mantener estable la operación de dicha máquina (Paloma, 2007).

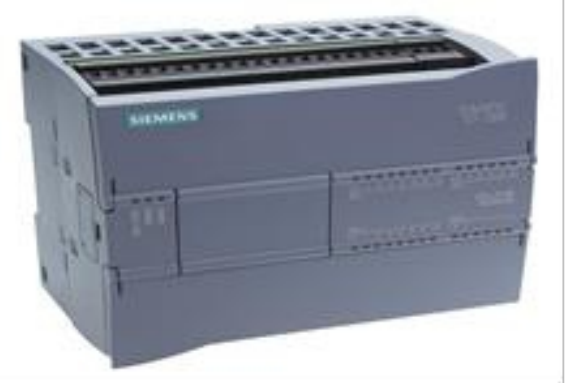

Figura 1. PLC Siemens S7-1200 CPU1214C

Fuente: https://mall.industry.siemens.com/mall/es/-WW/Catalog/Products/10045652

\section{Electroválvulas}

Las electroválvulas son dispositivos electrónicos y mecánicos diseñados para poder controlar el paso de fluidos, ya sea el aire, vapor, entre otros por una tubería; este paso puede ser controlado mediante la utilización de una bobina solenoide, generalmente con dos posiciones principales de abierto y cerrado (Mattarollo, 2014).

Las electroválvulas utilizadas fueron de 5/2 Monoestable, que tienen un solenoide en un extremo y un muelle en el otro extremo. Al alimentar el solenoide con 24 VDC la válvula cambiaba de posición, y una vez que se dejaba de alimentar la válvula este regresaba a su posición normal.

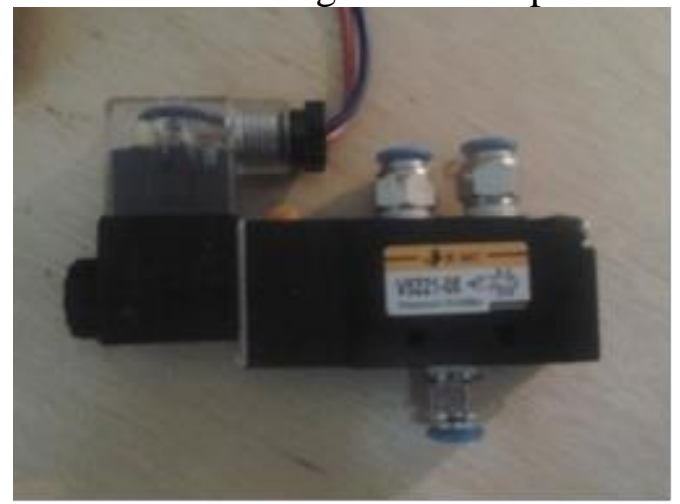

Gráfico 2. Electroválvula Monoestable 5/2 EMC

\section{Cámaras Digitales}

Se utiliza la técnica de visión artificial, y para ello fue necesario usar un dispositivo que sea sensible a la luz y que permitiera almacenar las imágenes en formato digital (Jiménez, 2000). 


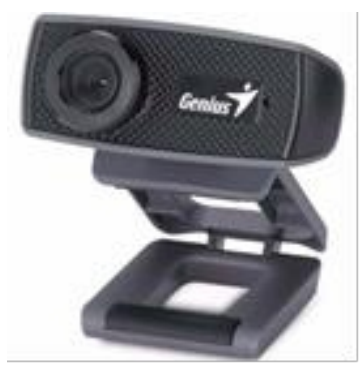

Figura 3. Cámara Web

Fuente: http://www.logitech.com/es-es/webcam-communications/webcams

\section{Sensores}

Los sensores son dispositivos diseñados para captar variaciones de tipo mecánico, magnético, térmico, óptico o químico y convertirlas en señales de tipo eléctrico para su posterior procesamiento y uso.Los sensores capacitivos de proximidad se encargan de la detección de materiales, ya sean estos metales o no metales, a una distancia específica de cada tipo de sensor sin necesidad de contacto.

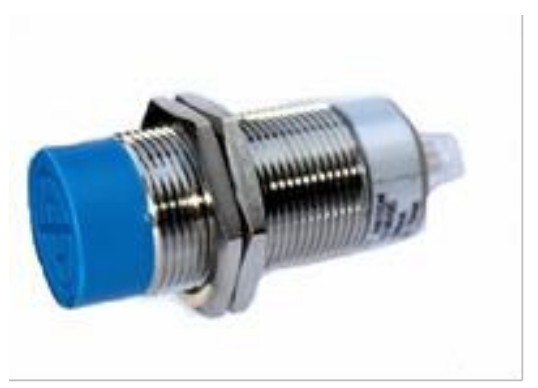

Figura 4. Sensor capacitivo

Fuente: $h t t p: / / w w w$. siriored.com/sensores

El sensor fotoeléctrico difuso posee el transmisor y el receptor en la misma carcasa. Este sensor emite un haz de luz hacia un objeto de medición que actúa como reflector y volviendo cierta cantidad de luz hacia el sensor y activándolo cuando se alcanza un valor umbral.

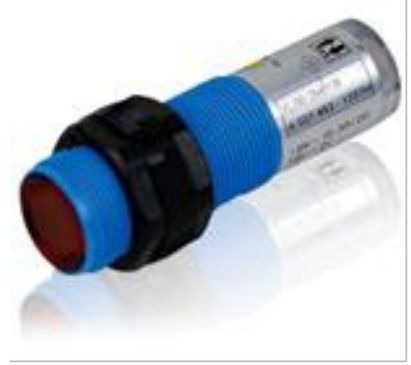

Figura 5. Sensor Fotoeléctrico difuso

Fuente: www.directindustry.es 
Los elementos conocidos como finales de carrera son dispositivos constituidos de partes mecánicas, los cuales permiten el paso de energía eléctrica a través de sus contactos; en el momento en que el dispositivo cierra por fuerzas externas sus contactos permiten el flujo de energía eléctrica.

\section{Resultados y Discusión}

\section{Diseño e implementación}

Se opta por los sistemas neumáticos y no por los actuadores eléctricos, como los motores, porque presentan las siguientes ventajas:

- Sencillez en los sistemas de mando.

- Facilidad en movimientos mecánicos.

- Costos de los actuadores neumáticos, más bajo con respecto a actuadores eléctricos.

El diseño e implementación del sistema automatizado SCADA contó con 3 procesos independientes pero secuenciales, monitoreados y controlados mediante Labview, estos son:

\section{Sistema neumático de control de compuertas.}

Se implementó con sensores fotoeléctricos colocados en la puerta principal de entrada de la sala de ordeño y en las compuertas de cada cubículo. Ante la presencia o ausencia del animal estos sensores enviaban señales al PLC, el mismo que de acuerdo a su programación activaba o desactivaba los actuadores o cilindros neumáticos que permiten la apertura o cierre de la puerta principal y las compuertas de los cubículos.

Los elementos del sistema neumático para la apertura y cierre de compuertas fueron los siguientes:

- Compresor 2HP

- Unidad de mantenimiento (Filtro Regulador Lubricador)

- 2 Válvulas monoestables $5 / 2$ activación por relé $24 \mathrm{~V}$

- 4 Cilindros neumáticos de $20 \mathrm{~cm}$ de recorrido 


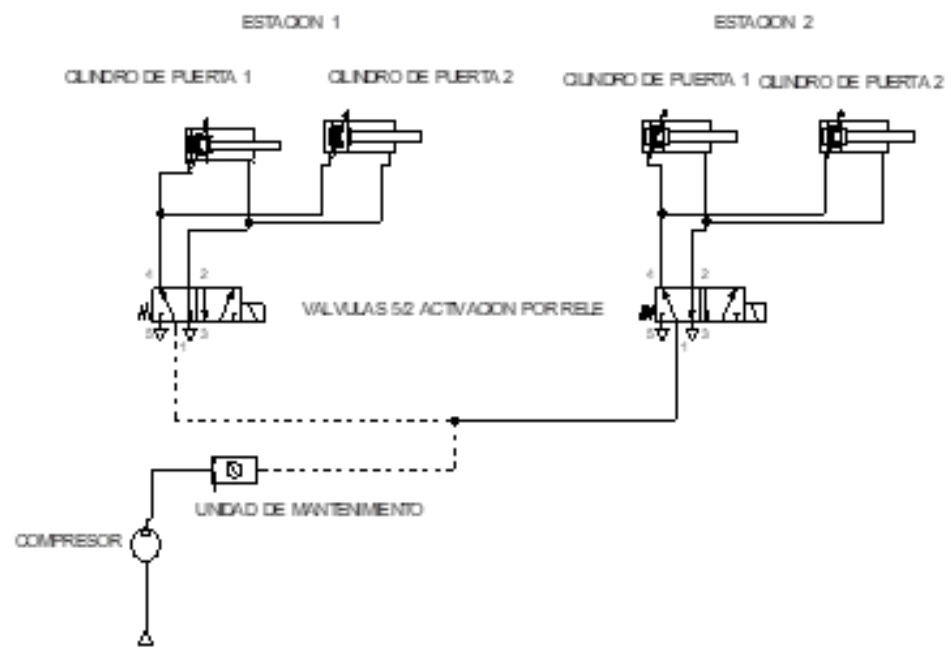

Figura 6. Diagrama neumático del sistema de puertas

\section{Sistema neumático de dosificación de alimento}

Se instaló una tolva en cada cubículo equipada con sensores capacitivos, electroválvulas y cilindros neumáticos. Mediante los sensores se determinó el nivel de alimento y mediante las electroválvulas neumáticas se activó el cilindro neumático que permitió la apertura o cierre de la tolva para dosificar la cantidad exacta de alimentación a cada animal.

Las tolvas fueron diseñadas de forma cónica, lo cual facilita la caída del alimento y permite reducir las acumulaciones que podrían variar la cantidad de dosificación como indica el Gráfico. 7.

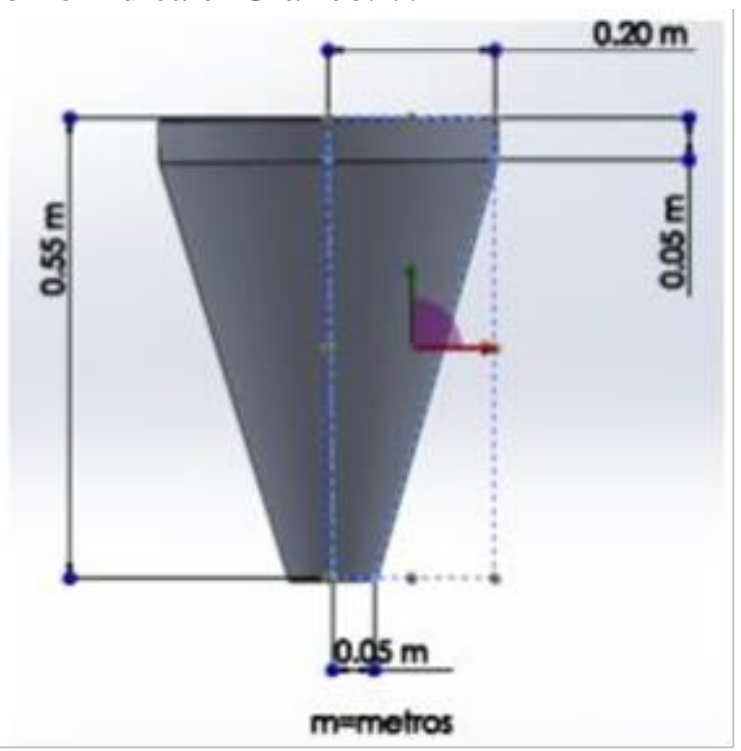

Gráfico 7. Diseño de Tolva (Depósito) 
Para calcular la capacidad de almacenamiento en $\mathrm{kg}$ del sistema de dosificación fue necesario calcular primero el volumen total del sistema de dosificación (vtotal) y multiplicarlo por la densidad del alimento.

$$
\begin{aligned}
& \text { vtolv } a=\frac{1}{3} \pi h\left(R^{2}+r^{2}+R r\right) \\
& \text { vtolva }=>\text { volumentowa } \\
& h=>\text { altura } \\
& R=>\text { Radiomayor } \\
& r \Rightarrow \text { radiomenor } \\
& \text { vtolva }=\frac{1}{3} \pi 0.55\left(0.20^{2}+0.05^{2}+0.20 \times 0.05\right) \\
& \text { vtolv } a=0.030238 \mathrm{~m}^{3}
\end{aligned}
$$

Para el dosificador se optó por un diseño de forma cilíndrica y se colocó su parte inferior el componente mecánico para la dosificación como indica el Gráfico.8.

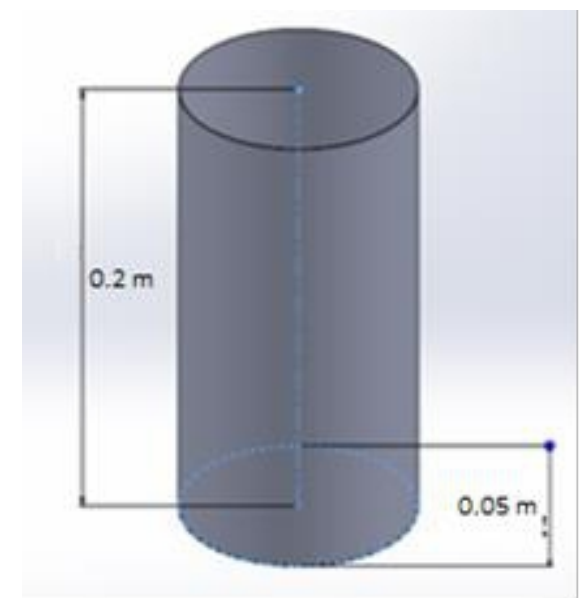

Gráfico 8. Diseño de Tolva (Depósito)

$$
\begin{aligned}
& v \text { dosificador }=\pi r^{2} h \\
& \text { vdosificador }=>\text { volumendosificador } \\
& h=>\text { altura } \\
& r=>\text { radiomenor } \\
& \text { vdosificador }=\pi \times 0.05^{2} \times 0.2 \\
& \text { vdosificador }=0.00157 \mathrm{~m}^{3}
\end{aligned}
$$

Reemplazando (1) y (2) se obtuvo el volume total del Sistema de dosificación.

$$
\begin{aligned}
& \text { vtotal }=\text { vtolva }+ \text { vdosificación } \\
& v \text { total }=0.03181 \mathrm{~m}^{3}
\end{aligned}
$$


Al final para calcular la cantidad de almacenamiento en $\mathrm{kg}$ del sistema de dosificación se multiplicó (3) por la densidad del alimento.

$$
\begin{aligned}
& m=\text { vtotal } \times d \\
& m=>\text { masa } \\
& d=>\text { densidad }\left(700 \frac{\mathrm{kg}}{\mathrm{m}^{3}}\right) \\
& m=0.03181 \mathrm{~m}^{3} \times 700 \frac{\mathrm{kg}}{\mathrm{m}^{3}} \\
& m=22.26 \mathrm{~kg}
\end{aligned}
$$

Cada tolva fue capaz de dosificar $22.26 \mathrm{~kg}$ de alimento sin la necesidad de recarga por parte del trabajador, reduciendoasí el esfuerzo físico y tiempo utilizado en esta actividad. Se reduce además un porcentaje considerable de los desperdicios generados por el sistema manual de alimentación. El diseño final de la tolva de $22.26 \mathrm{~kg}$ como se indica en el Gráfico 9.

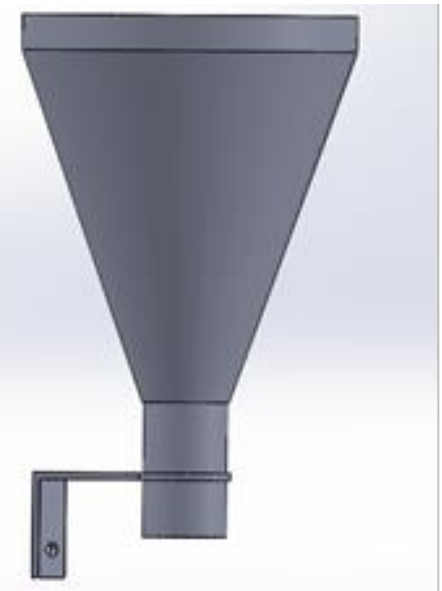

Figura 9. Diseño Final de la Tolva

El diseño y funcionamiento final del sistema neumático de dosificación se completa con los siguientes elementos:

Compresor $2 \mathrm{HP}$

* Unidad de mantenimiento (Filtro Regulador Lubricador)

* 2 Válvulas monoestables 5/2 activación por relé $24 \mathrm{~V}$

* 2 Cilindros neumáticos de $10 \mathrm{~cm}$ de recorrido

El diseño final se indica en el Gráfico 10. 


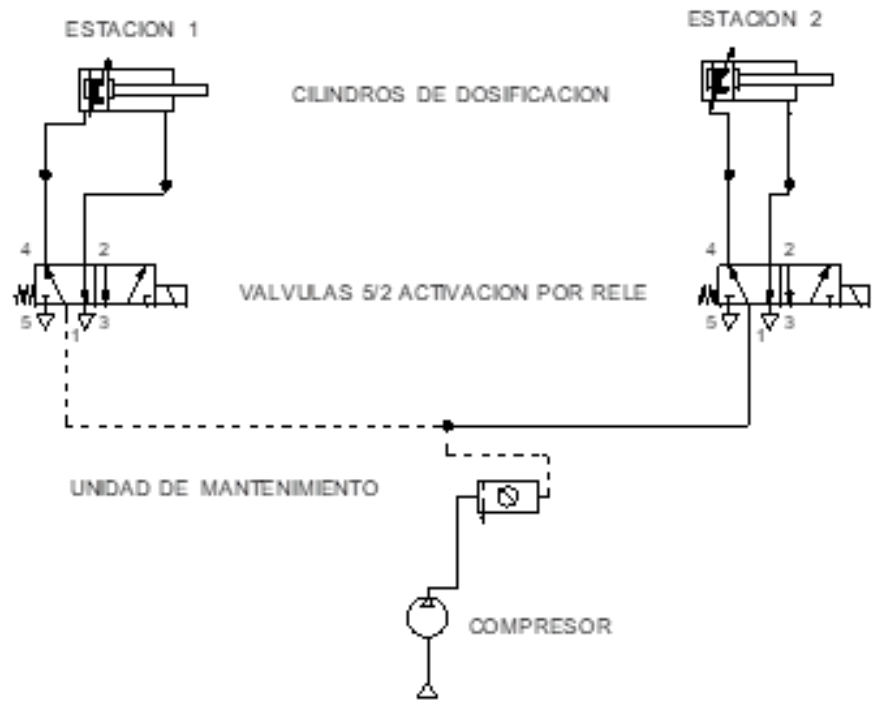

Figura 10. Diagrama neumático del sistema de dosificación

\section{Sistema de medición de leche}

Se ubicaron las cámaras Web frente a cada display o pantallas del sistema de ordeño semiautomático existente en la sala. Mediante el uso de sensores mecánicos (finales de carrera) se determinó el momento preciso en que se desprenden las pezoneras del animal y simultáneamente se captura la imagen desde las pantallas electrónicas para procesarla en Labview. La imagen capturada indicaba la cantidad de litros producidos y una vez procesada y convertida a formato decimal se almacenaba en una base de datos MySQL con el código de la vaca, fecha y hora, datos que posteriormente sirven para el sistema informático de gestión. Ver Gráfico11.

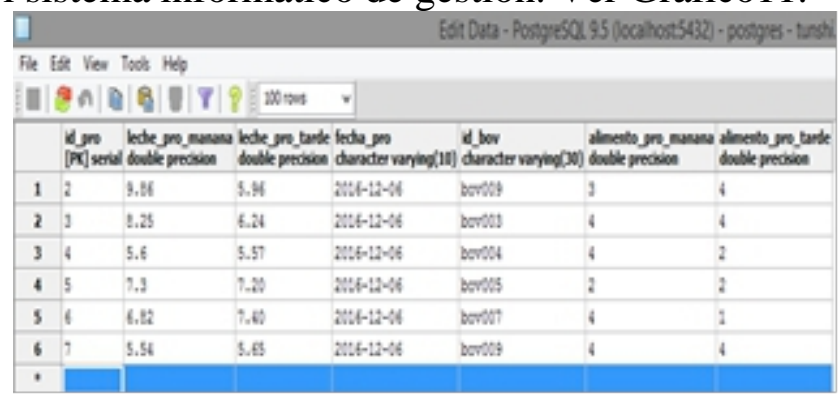

Figura 11. Tabla de Producción de la Base de Datos

\section{Aplicación visual desarrollada en Labview}

El sistema SCADA posee una interfaz para la interacción entre el operario y el sistema automático, el mismo que se instaló en la estación maestra (computador). Se diseñaron dos visualizadores; uno para mostrar la imagen capturada de cada una de las cámaras y el otro de tipo numérico que 
indica la cantidad de leche producida en formato decimal después de haber realizado el procesamiento de la imagen. Igualmente se colocan indicadores tipo booleano de color verde que indican si la tolva está vacía o con alimento, se ubican botones para el encendido o apagado del sistema, botones para la apertura o cierre de las compuertas de los cubículos, botones para la dosificación de alimento como opción redundante en caso de que fallen los sensores yse coloca también una sección para escoger el horario de ordeño y otra sección para eliminar registros de imágenes capturadas de forma errónea. Ver Gráfico12.

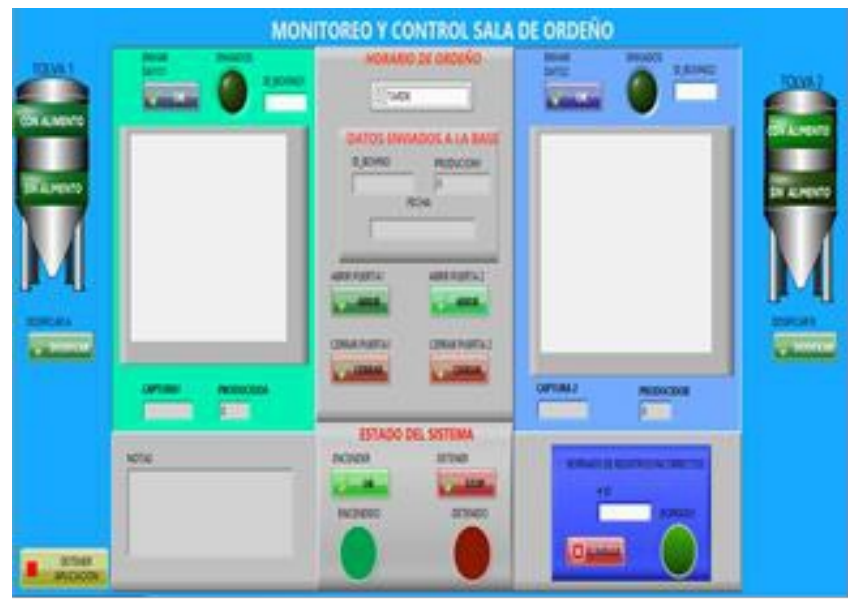

Figura 12. Interfaz de la aplicación creada en Labview

\section{Sistema SCADA}

En el Gráfico. 13.se visualizan mediante un diagrama de bloques todas las etapas del sistema donde se ubicaron los sensores y actuadores conectados al PLC que fue el encargado de manejar las señales eléctricas y convertirlas en datos que fueron almacenados en la base de datos y utilizados por el sistema informático de gestión y el sistema automático de control Labview.

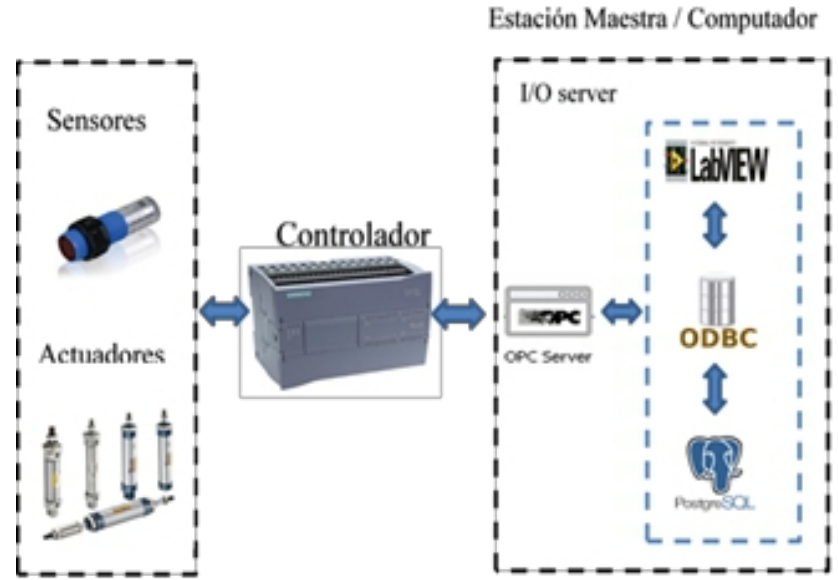

Figura 13. Esquema del sistema SCADA 


\section{Conexión de entradas y salidas al controlador}

El PLC SIEMENS S7 1200 1214C contaba con 14 entradas digitales, 2 entradas analógicas y 10 salidas digitales de las cuales sólo se utilizaron las entradas digitales, dejando las 2 entradas analógicas para posteriores expansiones del proyecto.

Las entradas digitales hacia el PLC provenientes de los sensores fotoeléctricos necesitan ser adecuados ya que estos son de tipo NPN y las demás entradas de sensores son PNP, de tal forma que un estándar de entradas hacia el PLC se logró mediante conversores de señal NPN a PNP como se ilustra en Gráfico 13., esto para no tener posteriores fallas en la programación del PLC al tener un solo puerto común en el PLC SIEMENSS7-1200. Establecidas las señales que utilizaba el PLC se pudieron determinar las entradas y salidas físicas del PLC que se utilizaron, como se indica en la Tabla 1.

\begin{tabular}{|l|l|l|}
\hline NOMBRE & DESCRIPCIÓN & ENTRADA \\
\hline Marcha & Botón verde & $\% \mathrm{I} 0.0$ \\
\hline Paro & Botón rojo & $\% \mathrm{I} 0.1$ \\
\hline Modo & Selector de 2 posiciones & $\% \mathrm{I} 0.2$ \\
\hline Sensor entrada & Sensor fotoeléctrico & $\% \mathrm{I} 0.3$ \\
\hline Sensor presencia estación 1 & Sensor fotoeléctrico & $\% \mathrm{I} 0.4$ \\
\hline Final de carrera 1 & Sensor mecánico & $\% \mathrm{I} 0.5$ \\
\hline Sensor tolva 1 vacía & Sensor capacitivo & \%I0.6 \\
\hline Sensor presencia estación 2 & Sensor fotoeléctrico & $\% \mathrm{I} 0.7$ \\
\hline Final de carrera 2 & Sensor mecánico & $\% \mathrm{I} 1.0$ \\
\hline Sensor tolva 2 vacía & Sensor capacitivo & $\% \mathrm{I} 1.1$ \\
\hline
\end{tabular}

Tabla 1. Descripción de entradas hacia el PLC

En la Tabla 2 se describieron las conexiones a las salidas físicas del PLC para los dispositivos, en su mayoría actuadores.

\begin{tabular}{|l|l|l|}
\hline NOMBRE & DESCRIPCIÓN & SALIDAS \\
\hline Luz inicio sistema & Luz piloto Verde & $\%$ Q0.0 \\
\hline Luz paro sistema & Luz piloto Roja & $\%$ Q0.1 \\
\hline Electroválvula puerta estación 1 & Electroválvula neumática & $\%$ Q0.2 \\
\hline Electroválvula tolva 1 & Electroválvula neumática & $\%$ Q0.3 \\
\hline Electroválvula puerta estación 2 & Electroválvula neumática & $\%$ Q0.4 \\
\hline Electroválvula tolva 2 & Electroválvula neumática & $\%$ Q0.5 \\
\hline
\end{tabular}

Tabla 2. Descripción de salidas del PLC 
Con las señales de entrada y salida descritas en la Tabla 1 y la Tabla 2 se diseñó el diagrama de conexión ilustrado en la Figura 14, donde se muestran las conexiones del PLC.

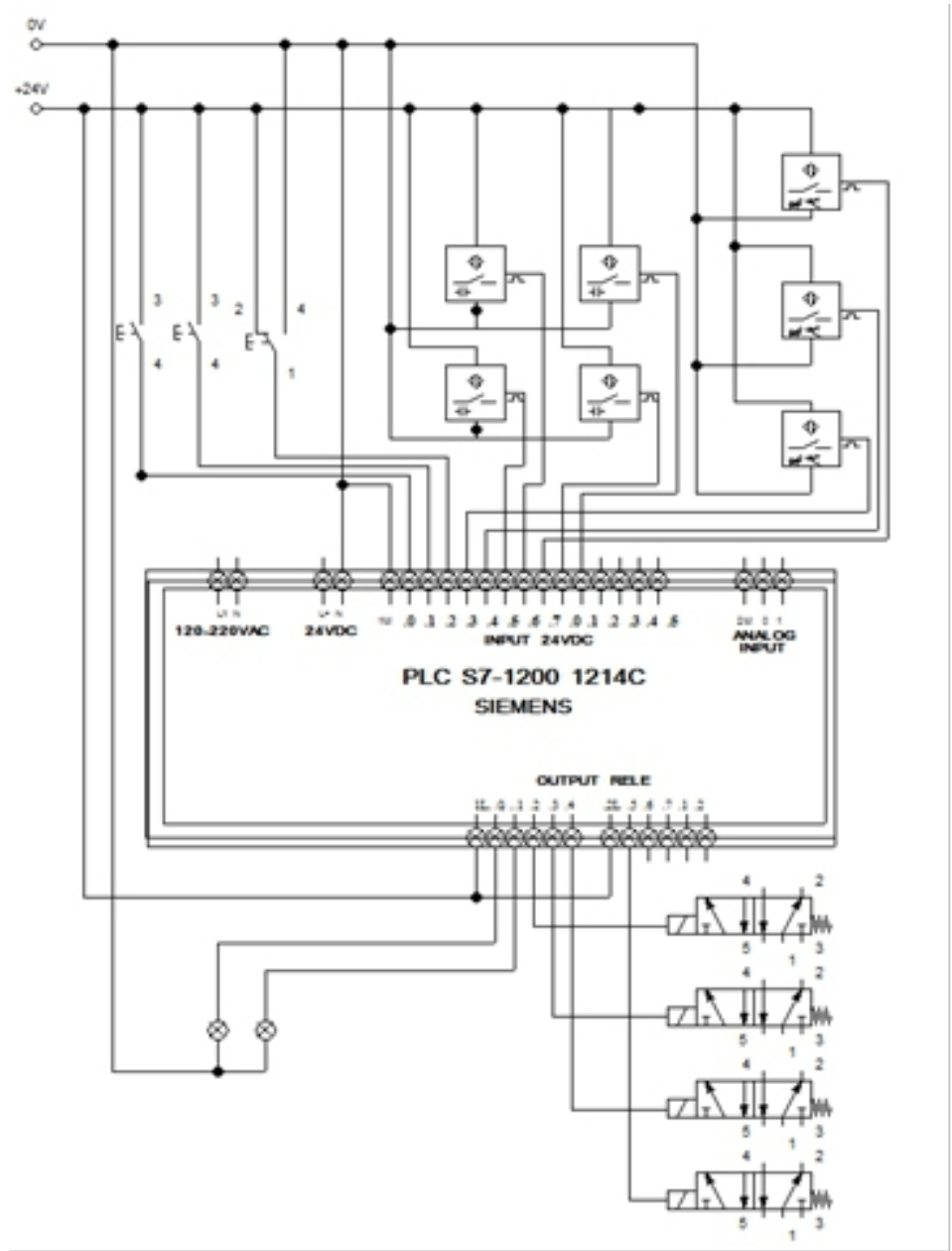

Figura 14. Diagrama de Conexiones al PLC

\section{Discusión}

Sistema neumático de dosificación de alimento

Tiempo de dosificación:

El sistema neumático de dosificación se calibra después de varias pruebas de funcionamiento para establecer el tiempo que debía estar activa la electroválvula para dosificar la cantidad de alimento requerida por cada vaca. Dichas pruebas se realizan a diferentes capacidades de la tolva para obtener el tiempo promedio de dosificación de $1 \mathrm{~kg}$, que es una ración promedio de alimento que consume cada vaca. 


\begin{tabular}{|l|l|l|l|}
\hline Tiempo (s) & $\begin{array}{l}\text { Frecuencia } \\
\text { Absoluta }\end{array}$ & $\begin{array}{l}\text { Frecuencia } \\
\text { Relativa }\end{array}$ & $\begin{array}{l}\text { Frecuencia } \\
\text { Relativa } \\
\text { Acumulada }\end{array}$ \\
\hline $\mathbf{0 . 5 7}$ & 6 & 0.30 & 0.30 \\
\hline $\mathbf{0 . 5 8}$ & 9 & 0.45 & 0.75 \\
\hline $\mathbf{0 . 5 9}$ & 2 & 0.10 & 0.85 \\
\hline $\mathbf{0 . 6 0}$ & 3 & 0.15 & 1.00 \\
\hline
\end{tabular}

Tabla 3. Tabla de frecuencias para tiempos de dosificación

Como se puede observar en la Tabla 3, existen dos valores que son predominantes en el tiempo de dosificación: el tiempo de 0.58 y 0.57 segundos.

Tomando en cuenta los resultados obtenidos se determina un tiempo promedio de 0.575 segundos para poder dosificar una ración promedio de 1 $\mathrm{kg}$. Se utiliza entonces dicho valor en la programación final del PLC. El tiempo de dosificación depende entonces de la cantidad de alimento en $\mathrm{kg}$ que consume cada vaca. Al tener un tiempo promedio de dosificación el sistema se adapta fácilmente a las nuevas cantidades de alimento en $\mathrm{kg}$ que podrían consumer las vacas posteriormente en el Centro Experimental Tunshi.

\section{Consumo de alimento:}

Durante el proceso de ordeño se determina mediante la utilización del sistema neumático de dosificación que se dosificó $1 \mathrm{~kg}$ por cada vaca, dando un total de $28 \mathrm{~kg}$ por las 28 vacas ordeñadas, y mediante el sistema manual de dosificación para el mismo número de vacas se utilizaba $36.4 \mathrm{~kg}$ de alimento, equivalente a $1.3 \mathrm{~kg}$ aproximadamente por cada una, lo que evidencia un mayor consumo y pérdidas de alimento.

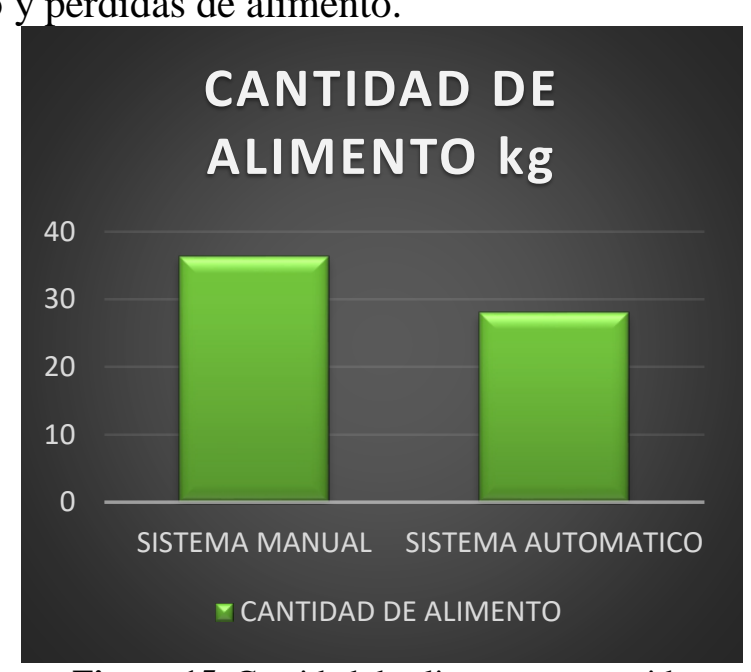

Figura 15. Cantidad de alimento consumido 
Se pudo determinar entonces que mediante el sistema neumático de dosificación se reduce en un $23.08 \%$ la cantidad de alimento utilizada con respecto al sistema manual, reduciéndose así los gastos de alimentación en el proceso de ordeño.

\section{Sistema de medición de leche}

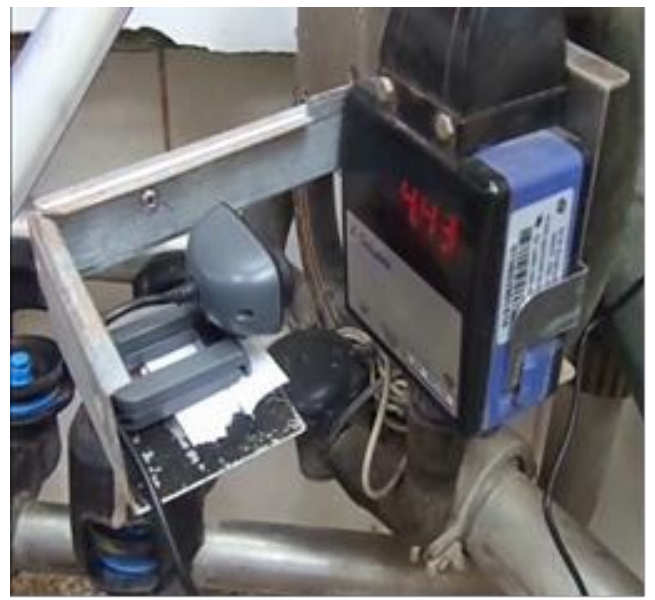

Figura 16. Localización de cámaras

Mediante LabVIEW se logró convertir la imagen tomada por la cámara a formato decimal y almacenar en la base de datos la cantidad de litros producidos por cada vaca. Esto prueba que la calibración de las cámaras es correcta, así como también la programación para el procesamiento de imágenes (ver Figura 16.). Si existen imágenes mal tomadas debido al exceso de iluminación o ruido en el ambiente, el sistema muestra un símbolo de interrogación y almacena un valor de cero en la base de datos, pero la programación correcta en LabVIEW permitía tomar nuevamente la imagen y volverla a procesar en milésimas de segundo para mostrar en la pantalla del sistema y almacenar el valor correcto en la base de datos (Figura 17). 


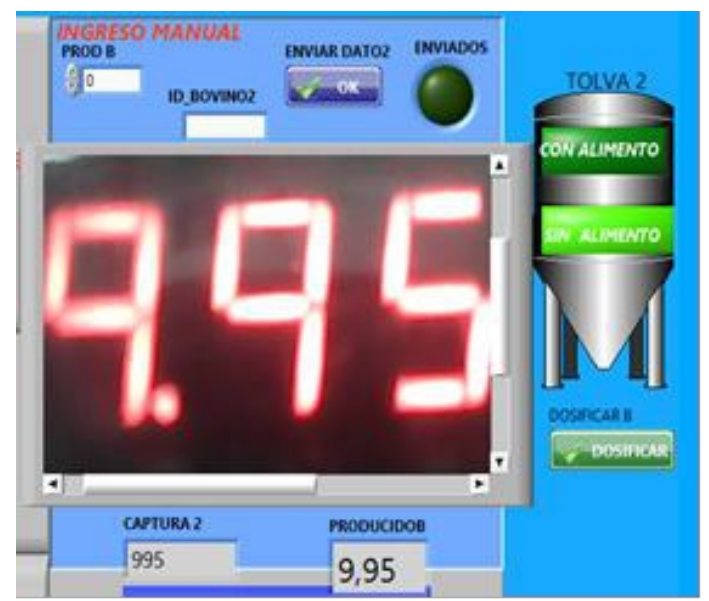

Figura 17. Lectura de producción en LabVIEW

Al comparar con el sistema manual, se logró optimizar este proceso ya que la información producida por el sistema manual era registrada en hojas de cuaderno por parte de los operarios dando lugar a errores de apuntes y de digitación al registrar estos datos en hojas de cálculo de Excel para tener un histórico de la producción de leche.

\section{Sistema de control de compuertas}

El sistema de control de compuertas para apertura y cierre se puede implementar gracias a los sensores fotoeléctricos localizados estratégicamente fuera y dentro de la sala de ordeño, los cuales indicaban la posición del animal y enviaban una señal para el accionamiento de la electroválvula neumática que permite el movimiento del actuador (ver Figura 18). Dichos actuadores se calibran para tener un movimiento lento y evitar daños físicos a las vacas o desgastes innecesarios en compuertas; esto depende del nivel de presión controlado por la unidad de mantenimiento neumática que se encotraba en 20 Psi.

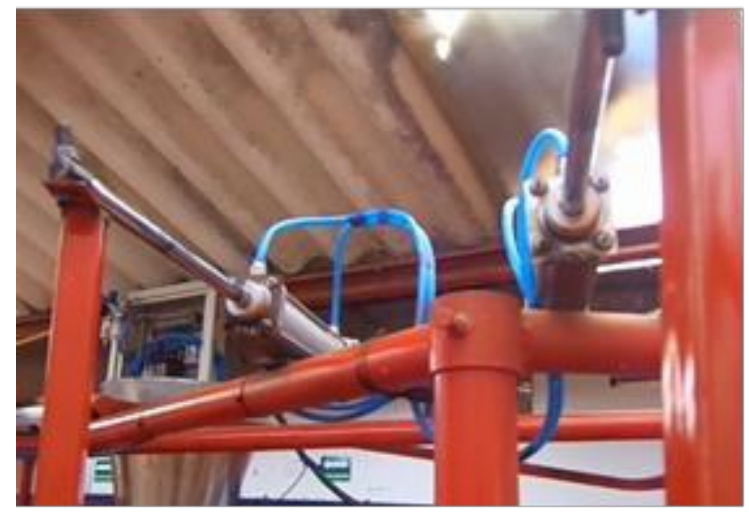

Figura 18. Sistema neumático implantado 
El sistema SCADA permitió la apertura y cierre de compuertas de forma automática sin la intervención física de los obreros, optimizando de esta manera el tiempo y los recursos como indica la Figura 19.

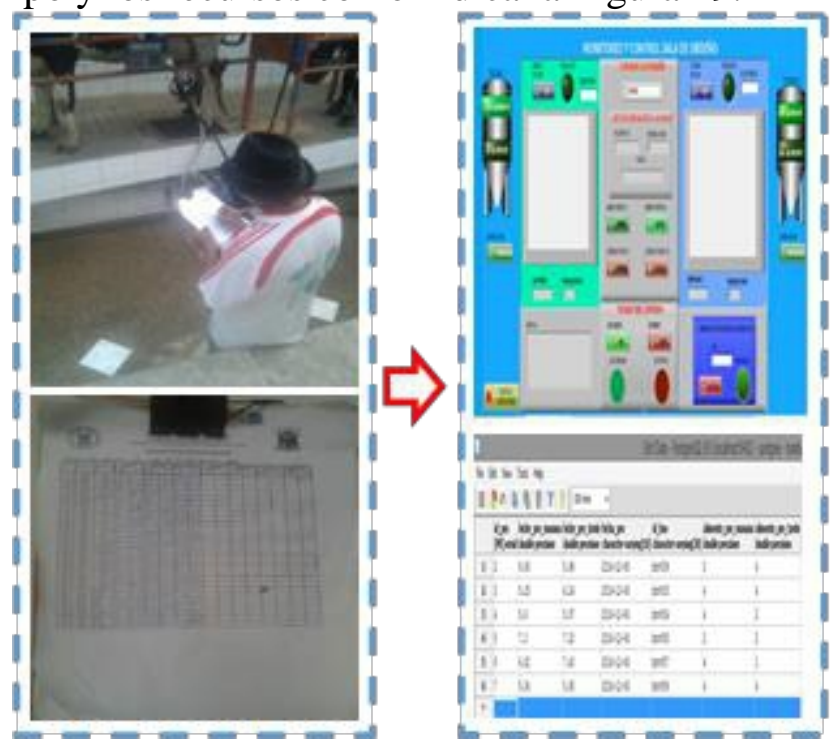

Figura 19. Cambio en el manejo de la información

\section{Conclusiones}

1. En la explotación ganadera no se aplican adecuadamente la ciencia y la técnica y esto se erige como una de las principales causas de los malos resultados económicos de este sector productivo.

2. La automatización de los principales procesos productivos en la ganadería constituye una necesidad impostergable que, no sólo humaniza el trabajo, sino que también permite optimizar el uso de los recursos disponibles y poseer la informción apropiada para la toma de decisiones.

3. La implementación del sistema automatizado propuesto satisface los requerimientos de los procesos de ordeño, permite dosificar la cantidad necesaria de alimento a cada vaca, evita los desperdicios de alimento, ayuda significativamente al estudio y mejoramiento de ganado vacuno de leche, y optimiza además tiempo y recursos humanos.

4. El sistema automatizado propuesto es viable para aplicarse a gran escala debido a sus bajos costos de implementación y facilidad de manejo.

\section{Recomendaciones}

1. Para optimizar el funcionamiento del sistema automático de apertura y cierre de compuertas se recomienda rediseñar a futuro un sistema 
mecánico de ordeño que reduzca al mínimo la fricción y evite bloqueos de accionamiento automático de compuertas.

2. Utilizar sensores de caudal externos colocados en las mangueras de succión, ya que debido a los cambios de iluminación y vibraciones generadas por el sistema de ordeño se requiere la calibración de las cámaras antes de iniciar el proceso de ordeño.

3. Potenciar el uso de sistemas neumáticos en los sistemas de automatización de los procesos de ordeños por ser más silenciosos que los mecánicos; de este modo se evitan variaciones significativas en los resultados causadas por el poco predictible comportamiento animal.

\section{References:}

1. Boyer \& Stuart (2009). SCADA: Supervisory control and data acquisition. International Society of Automation.

2. Cobo Ruiz, T. (2015). Estudio de viabilidad económica de la implantación de un sistema de ordeño robotizado en una explotación ganadera de bovino.

3. Duque, M., Carlos, J., Ospina, J. D., Piraqive, V., \& Alejandro, M. (2015). Diseño y desarrollo de prototipo automatizado de comedero para ganado (Bachelor's thesis).

4. Filgueira, G. G. \& Raimúndez, G. F. (2012). Automatización de una sala de ordeño tipo tándem.

5. Jiménez, J. G. (2000). Visión por computador. Paraninfo.

6. Mattarollo, Y. (2014). Altec. Monterrey, México: Cómo funcionan las electroválvulas o válvulas solenoides de uso general. Recuperado de http://www.altecdust.com/blog/item/32-como-funcionan-laselectrovalvulas-o-valvulas-solenoides-de-uso-general

7. MONOGRAFICO. Lenguajes de programación - Principios básicos de PLC. Observatorio Tecnológico. [En línea].

8. Paloma, P. (2007). Ministerio de Educación, Cultura y Deporte. España: Lenguajes de Programación-Principios Básicos del PLC. Recuperado de http://recursostic.educacion.es/observatorio/web/gl/component/conte nt/article/502-monografico-lenguajes-de-programacion?start=2

9. Torres, Y., Rivas, J., Pablos-Heredero, D., Perea, J., Toro-Mujica, P., Angón, E., \& García, A. (2014). Identificación e implementación de paquetes tecnológicos en ganadería vacuna de doble propósito: Caso Manabí-Ecuador. Revista mexicana de ciencias pecuarias, 5(4), 393407. 